\title{
Influence of Aeration Rates on Oxygen Mass Transfer and Flow- Field in a Microporous Aeration System
}

\author{
Cheng Lü ${ }^{1,2}$, Wen Cheng ${ }^{1 *}$, Zhen Li $^{3}$, Min Wang ${ }^{1}$, Jikai Liu ${ }^{1}$ \\ 'Institute of Water Resources and Hydro-Electric Engineering, Xi'an University of Technology, Xi'an 710048, China \\ ${ }^{2}$ School of Architecture \& Civil Engineering, Xi' an University of Science \& Technology, Xi'an 710055, China \\ ${ }^{3}$ Henan Sanjian Construction Group Co. LTD, Luoyang 471000, China
}

Received: 23 July 2020

Accepted: 17 November 2020

\begin{abstract}
Microporous aeration is extensively used, and oxygen mass transfer during aeration has a direct impact on water remediation. Nevertheless, the research on the mechanism of oxygen mass transfer in microporous aeration is lacking. This study aimed to explore the variation in oxygen mass transfer from the bubble-movement flow-field in a microporous aeration system. Then, the characteristic parameters of oxygen mass transfer and bubble movement (by particle image velocimetry) were determined under different aeration rates. Results showed that aeration rates were significantly positively correlated with bubble number $(\mathrm{R}=0.98)$, bubble-movement velocity, total oxygen-mass-transfer coefficient $\left(K_{L} a\right)$, and oxygenation capacity $\left(\mathrm{R}^{2}=0.98,0.98\right)$. This finding indicated that the increase in bubble number and bubble-movement speed accelerated the oxygen mass transfer and improved oxygenation performance and $K_{L} a$. Moreover, a significant positive correlation existed between aeration amount and average Sauter diameter $(\mathrm{R}>0.97)$, but a significant negative correlation existed between aeration amount and specific bubble surface area $(R<-0.98)$. Thus, increased aeration amount led to increased average bubble Sauter diameter. These phenomena further led to decreased specific bubble surface area and $E_{A}$. Overall, these results can guide the research on oxygen-mass-transfer mechanism from the perspective of bubble-movement flow-field.
\end{abstract}

Keywords: aeration, bubble movement, flow-field, PIV, oxygen mass transfer

\section{Introduction}

Eutrophication waters are becoming a serious problem in many parts of the world. Several technologies

*e-mail: wencheng@xaut.edu.cn

such as sludge dredging [1], chemical coagulation [2], bioremediation [3], the addition of mulch [4-5], and artificial aeration [6] have been developed to control and mitigate eutrophication. Among them, artificial aeration is extensively used because of its advantages of simple operation, low cost, and quick effect.

At present, the main artificial-aeration technologies are mechanical aeration, water-lifting aeration, and 
blast aeration. Mechanical aeration has the advantages of convenient operation and management, simple equipment structure, etc. However, it also has the disadvantages of high energy consumption, uneven gas production, and complicated maintenance. The installation and maintenance of water-lifting aeration equipment is also difficult and the energy consumption is large, so it is inconvenient for large-scale application. Meanwhile, blower-aeration system has the advantages of simple structure, low energy consumption, simple maintenance, low noise, and high oxygen-utilization rate [7]. In addition, micro-bubble aeration in an air-blast aeration system has advantages in water-quality repair. $\mathrm{Hu}$ [8] found that aeration has a good inhibitory effect on the release of $\mathrm{COD}$ and $\mathrm{NH}^{3}-\mathrm{N}$ after microporous aeration treatment of water from Wuyu River in Beijing. Lu [9] explored the restoration effect of micronano aeration on urban landscape water bodies. Thus, microporous aeration [10, 11] is gradually becoming extensively used in artificial aeration technology due to its advantages of low energy consumption and high efficiency. The linear microporous hose aeration system as a micro-bubble aeration system has been well applied in the Tennessee Valley [12]. The oxygen-transfer efficiency of this technology can reach more than $90 \%$ in deep water [13]. However, with decreased water depth, the oxygen-utilization rate gradually decreases. When the water depth is $2-5 \mathrm{~m}$, the oxygen-utilization rate is generally around $15 \%$ [14], which causes a large amount of energy waste and thus greatly limits the popularization and application of the linear microporous hose aeration. Therefore, the methods of improving the efficiency of gas-liquid-oxygen mass transfer are worth exploring.

The theoretical description of oxygen mass transfer has been well described [15-17]. The oxygen mass transfer of microporous hose aeration is affected by many factors, such as pore diameter, aeration gas volume, and depth at which aeration occurs [18,19]. Other factors affecting oxygen mass transfer are flow pattern, shear stress, size of bubbles and their size distribution, and operational conditions [20,21], as well as bubble collisions and coalescence events as bubbles rise, and their velocity [22-27]. Nevertheless, most studies focus on external parameters such as aeration parameters and aeration mode, and the influence of bubble movement of microporous aeration on oxygen mass transfer is rarely studied. The bubble group produced by the microporous hose belongs to the bubble plume, and the gas-phase flow-field generated by the bubble plume during the rising process greatly influences the oxygen mass transfer. Many studies have been conducted on bubble plumes, for example, Simiano [28] conducted statistical analysis on the distribution and instantaneous diameter of the center of bubble plumes. Rensen [29] conducted an experimental study on the unstable structure of two-dimensional bubble plumes. Cheng [30] discussed the variation law of instantaneous and time-averaged velocity field distribution of bubble plume under different aspect ratios, voidage, and pressure in simulated aeration vessels. Based on particle image velocimetry (PIV) measurement technology and experimental research, Wang [31] determined the specific distribution of gasphase velocity field in the aeration process through further numerical simulation. Xiao [32] studied the rule of bubble wall effect in the aeration process through experiments. Most of the above studies are based on hydraulics on the change rules of bubble plume flowfield and flow characteristics, and only a few have focused on the influence of bubble plume on oxygen mass transfer. Therefore, oxygen mass-transfer theory is necessary to study from the perspective of bubblemovement flow-field to better explore the microscopic mechanism of oxygen mass transfer.

Indeed, the correlation between the movement rule of bubble plume and the law of oxygen transfer in a microporous aeration system needs to be further explored. Accordingly, in the present study, linear microporous hose aeration was conducted to experimentally determine the bubble plume and oxygenmass-transfer characteristics under different aeration rates. The correlation between plume-movement characteristics and oxygen transfer law was analyzed, and then the microscopic mechanism of oxygen transfer characteristics under different aeration rates was explained on the perspective of bubble-movement flowfield. Our results can provide a certain theoretical basis for improving aeration capacity and water quality, as well as reducing the operating cost of aeration systems.

\section{Materials and Methods}

\section{Experimental Setup}

The experimental equipment is schematically shown in Fig. 1. A transparent reactor tank $(100 \mathrm{~cm}$ height $\times$ $60 \mathrm{~cm}$ length $\times 45 \mathrm{~cm}$ width) is equipped with a rubber microporous aeration hose (length $50 \mathrm{~cm}$ ) with a pore diameter of $200 \mu \mathrm{m}$ (Wuxi Aerating Equipment Co., Ltd., Jiangsu, China). The hose is fixed $5 \mathrm{~cm}$ above the bottom of the tank on a metal support, and the tank is filled with tap water of ambient temperature (water column height: $90 \mathrm{~cm}$ ). Atmospheric air is pumped in using an oil-free air compressor at five different flow rates $(150,200,250,300$, and $350 \mathrm{~L} / \mathrm{h})$ as determined by a gas-rotor flow meter. Airflow is regulated and controlled with a rotameter, and feed pressure is kept constant at $100 \mathrm{kPa}$ by using a pressure gauge to avoid minor compressor fluctuations. During air flow, an LDY300 laser (pulse lasers) positioned above the center of the tank and directly above the aeration hose at a height of $30 \mathrm{~cm}$ above the water level directed light (460-510 nm) from above.

Bubble flow is detected with a PIV camera (Dantec Dynamics A/S, Denmark). PIV measurements are taken in the vertical plane at a right angle to the orientation 


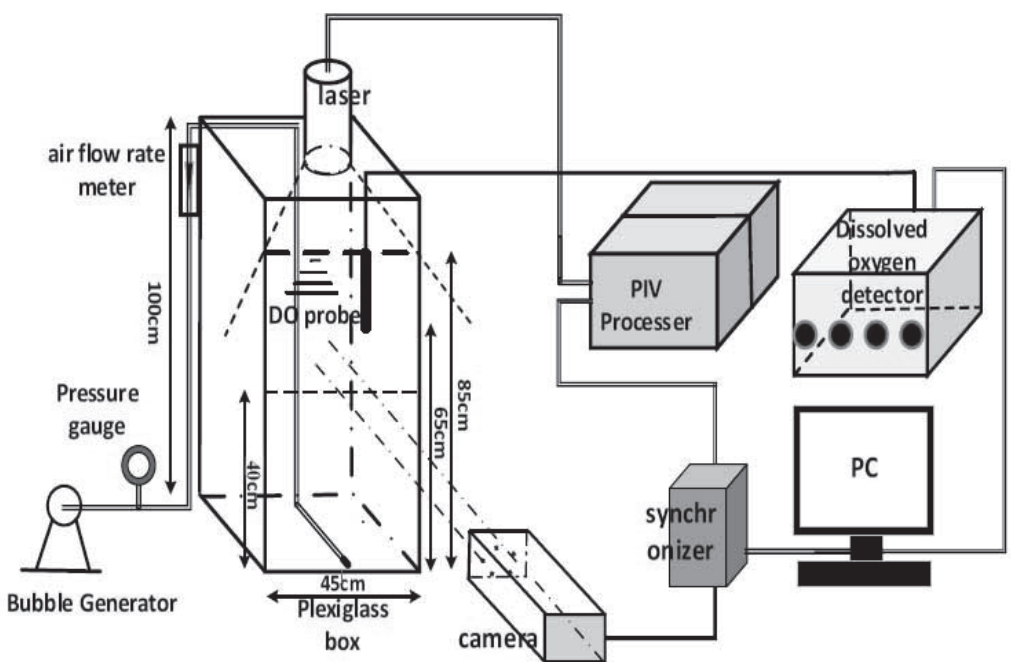

Fig. 1. Schematic of the experimental setup.

of the hose (Fig. 1) at a water depth of 40-85 cm (when the generated bubbles had ascended by at least $60 \mathrm{~cm}$ ) over a width of $45 \mathrm{~cm}$, giving an observation area of $45 \times 45 \mathrm{~cm}^{2}$. The area of observation is about $0.2-2 \mathrm{~mm}$ thick, as determined by the PIV equipment. This area is recorded with the PIV camera that sent images to an image-processing system in real time. Dissolved oxygen (DO) is measured simultaneously with the water temperature (accuracy $0.01^{\circ} \mathrm{C}$ ) by using a probe placed at a depth of $20 \mathrm{~cm}$ below the water surface and located exactly above the hose of a DO detector (PreSens, Regensburg, Germany).

\section{Determination of Oxygen-Transfer Coefficient}

Measurements were performed to monitor the degree of oxygenation and calculate the oxygenutilization rate and the total oxygen-mass-transfer coefficient $\left(K_{L} a ; h-1\right) . K_{L} a$ was used to analyze the physical dynamic gassing-out method as described by Moutafchieva et al. [33]. First, anoxic water was created by flushing pure nitrogen through the water until the DO concentration dropped below $0.8 \mathrm{mg} / \mathrm{L}$. When this state was reached, compressed air was injected through the hose. Furthermore, DO concentration and water temperature were recorded every 3 min until oxygen saturation was reached. For theoretical considerations, the classical dual-membrane theory originally proposed by using Lewis and Whitman that describes a logdeficit dependence (Eq. (1)).

$$
\ln \left(C_{s}-C_{t}\right)=\ln C_{s}-K_{L} a * t
$$

...where $C_{s}\left[\mathrm{mg} \cdot \mathrm{m}^{-3}\right]$ is the DO saturation concentration, and $C_{t}\left[\mathrm{mg} \cdot \mathrm{m}^{-3}\right]$ is the DO concentration in the tank at time $\mathrm{t}$ (in $\mathrm{min})$. When plotting $\ln \left(C_{s}-C_{t}\right)$ against $\mathrm{t}$, the slope of the curve gave $K_{L} a$. To eliminate the influence of temperature, $K_{L} a$ was corrected to $20^{\circ} \mathrm{C}$ by applying (Eq. (2)) [34]:

$$
K_{L} a_{(20)}=K_{L} a_{T} * 1.024^{(20-T)}
$$

$K_{L} a$ is an important indicator of oxygen mass transfer, with basic equations as follows (Eq. (3)):

$$
\begin{gathered}
d C / d t=\left(K_{L} * A / V\right) *\left(C_{S}-C_{t}\right)=K_{L} * a *\left(C_{S}-C_{t}\right) \\
K_{L} a=K_{L} * A / V
\end{gathered}
$$

...where $d C / d t\left[\mathrm{mg} \mathrm{O}^{2} \cdot \mathrm{m}^{-3} \cdot \mathrm{h}^{-1}\right]$ is the oxygen-transfer rate, $K_{L}\left[\mathrm{~m} \cdot \mathrm{h}^{-1}\right]$ is the molecular-mass-transfer coefficient of oxygen in a liquid film, $A\left[\mathrm{~m}^{2}\right]$ is the total surface area in the gas-liquid contact, and $\mathrm{V}\left[\mathrm{m}^{3}\right]$ is the volume of the liquid phase.

In addition, the formulas used to calculate the oxygenation capacity and oxygen-utilization rate are expressed by (Equation. (4) and (5)):

$$
\begin{gathered}
O C=K_{L} a_{(20)} * V *\left(C_{S}-C_{0}\right) \\
E_{A}=O C * 100 \% /(N * Q)
\end{gathered}
$$

...where $O C\left[\mathrm{mg} \cdot \mathrm{h}^{-1}\right]$ is the oxygenation capacity, $C_{0}$ is the initial $D O$ concentration, $E_{A}(\%)$ is the oxygenutilization rate, $N\left[\mathrm{mg} \cdot \mathrm{m}^{-3}\right]$ is the weight of oxygen in $1 \mathrm{~m}^{3}$ air under standard conditions (with value 0.28 ), and $Q\left[\mathrm{~m}^{3} \cdot \mathrm{h}^{-1}\right]$ is the aeration flow that was experimentally varied. For practical reasons, $Q$ is expressed in $\mathrm{L} / \mathrm{h}$ in the presented figures.

\section{PIV Measurements and Image Processing}

The CCD high-speed camera was focused on the center of the observation area described in section 2.1. To ensure a clear image of the flow-field, the laser light source was optimized for light intensity and uniformity before shooting. The optimum laser 
frequency had been determined as $7.4 \mathrm{~Hz}$ in pilot experiments. The experiment was started by opening the air compressor and adjusting the pressure gauge as per readings of the rotameter. When the bubble flow was stable (stable bubble flow was generally achieved in $1 \mathrm{~min}$, and considering accuracy, bubble-movement images were obtained after $6 \mathrm{~min}$ ), the movement of the generated bubbles was observed in real time with images electronically stored at interval times of $0.2 \mathrm{~s}$. This shooting frequency had been optimized from pilot experiments. Per experiment, a total of 25 images were recorded, covering a period of $5 \mathrm{~s}$. Under this condition, the bubbles could rise at least $45 \mathrm{~cm}$.

Raw images were processed before analysis to enhance the grayscale and image-edge segmentation. For the first, spatial gray transformation technology was used by applying the MATLAB software, which did not change the position of image pixels as it affected only the grayscale value of each pixel (Fig. 2). A histogram of the grayscales of pixels of each raw image was generated using the function IMHIST, which before adjustment ranged within 0-255 (Fig. 2b), but the vast majority of pixels were in a narrow range of 8-28 only. The corresponding image was mostly dark. Furthermore, bubbles were hardly visible (Fig. 2a). After extending the contrast, distribution uniformity increased (Fig. 2d). Finally, the bubbles were clearly visible (Fig. 2c).
The second correction was based on thresholdsegmentation technology. The edge, defined as the region within an image where the grayscale changed most strongly, was identified using PREWITT to improve contrast in Fig. 3.

\section{Calculation of Bubble Velocity}

The velocity of bubble movement was calculated from the generated images based on a comparison of two images from two consecutive time points, as explained below. Given that the laser was used in dual mode, the instantaneous velocity of individual bubbles could also be calculated. Accordingly, set of two images that were taken only a few milliseconds apart was produced for each time point. Depending on the gas flow (which was varied) this pulse interval time was varied between $6-10 \mathrm{~ms}$, which ensured that the displacement that was sufficiently small to follow individual bubbles along their course and to calculate their instantaneous velocity. From the instantaneous velocity of multiple bubbles per time point, the velocity distribution of the flow-field per time point was obtained.

The average velocity was obtained by dividing the observed displacement of the bubbles between two consecutive images for two time intervals. The signals of two consecutive frames (two time points) had to be matched to one and the same bubble, which was enabled a)

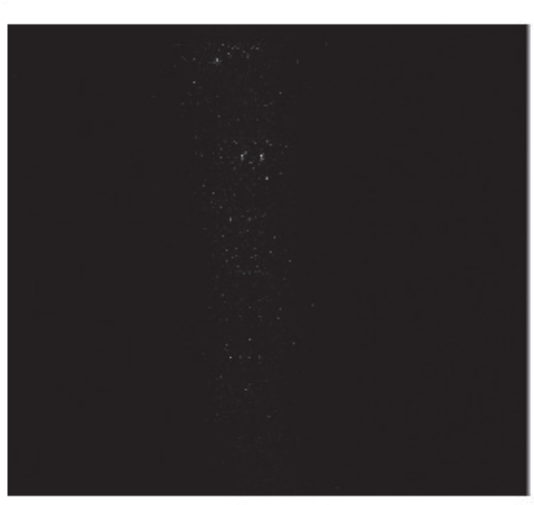

c)

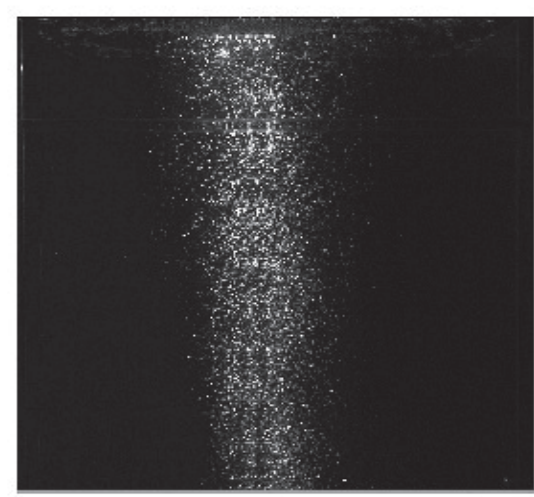

b)

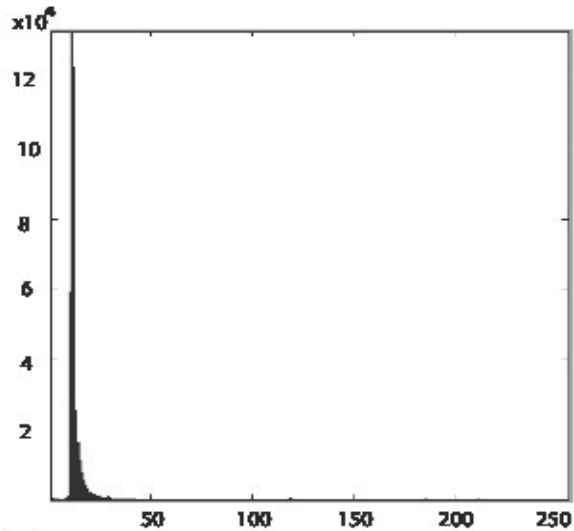

d) $\times 14$

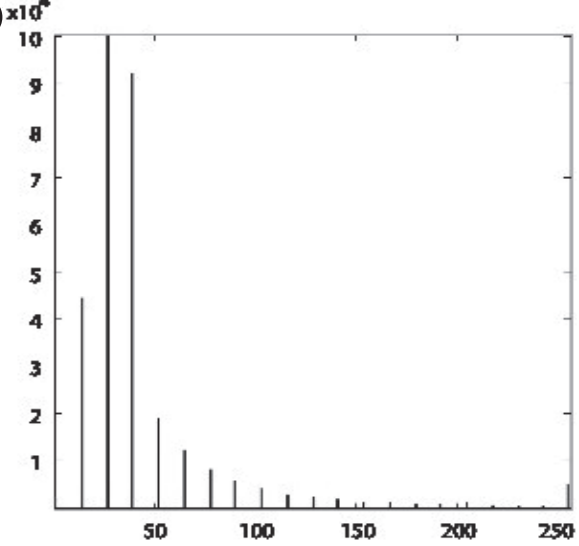

Fig. 2. Grayscale correction of PIV images. Shown are images (a, c) and grayscale distribution histograms (b, d) before (a, b) and after (c, d) grayscale correction. 
a)

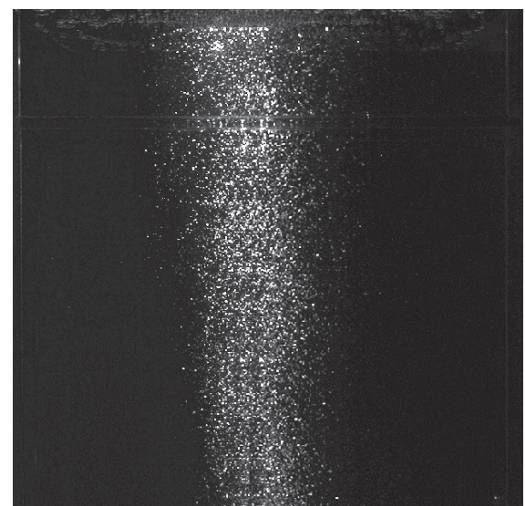

b)

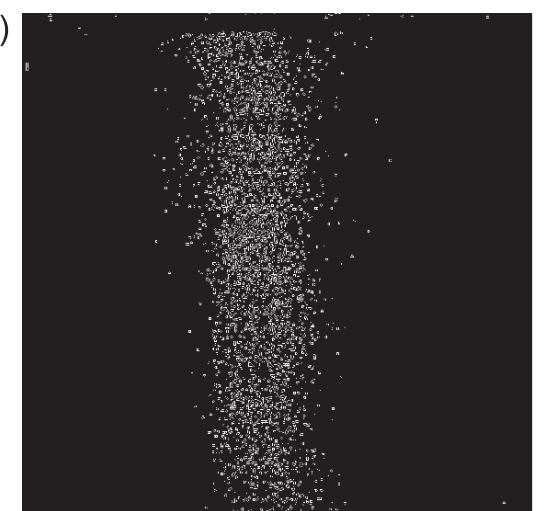

Fig. 3. Correction of PIV images by edge extraction using the PREWITT operator. Shown is a threshold-segmentation image before a) and after threshold segmentation $b$ ).

by cross-correlation using the Adaptive Correlation module of the PIV software. Due to the large image area captured by the camera, each image was divided into a grid of $64 \times 64$ query windows (one window covered approximately $70 \times 70 \mathrm{~mm}$ ) to ensure bubbles did not move by more than half of a grid unit.

After obtaining the bubble-displacement positions, their velocity $w$ was calculated using Eq. (6):

$$
\left\{\begin{array}{l}
u(x, y)=S_{X} * k / d t \\
v(x, y)=S_{y} * k / d t
\end{array}\right.
$$

...where $S_{x}[\mathrm{~mm}]$ and $S_{y}[\mathrm{~mm}]$ are the particle displacements in the $x$ and $y$ directions, respectively; $k$ is the actual length of a unit pixel; $d t[\mathrm{~s}]$ is the time interval between two time points; $u(x, y)[\mathrm{m} / \mathrm{s}]$ is the velocity in the $\mathrm{x}$ direction; and $v(x, y)[\mathrm{m} / \mathrm{s}]$ is the velocity in the $\mathrm{y}$ direction. The calculated bubble velocity $w$ is given by the vector sum of velocities $u$ and $v$, and $w$ was visualized in a heatmap using TECPLOT software.

\section{Calculation of Bubble Size and Surface Area}

The Shadow module in the PIV software was used to determine the diameter of bubbles. Individual bubbles were identified from the images as described above and counted per grid unit by using the bubblesize distribution law [35]. Most bubbles had an oval shape with a shorter axis in their direction of upwards travel. After determining the diameter of their short axis $h_{i}$ and their long axis $l_{i}$, the equivalent diameter $\left(d_{b i}\right)$ was calculated using Eq. (7) which gave the diameter of bubbles that were spherical [36].

$$
d_{b i}=\sqrt[3]{\left(h_{i} l_{i}\right)^{2}}
$$

The surface area $S_{A}$ of the bubbles was calculated with $S_{A}=4 \pi\left(d_{b i} / 2\right)^{2} . S_{T}$ represents the total surface area of a bubble to a large extent, and it represents $a$ in equation (3). The volume of bubble $V=4 \pi\left(d_{b i} / 2\right)^{3} / 3$. The specific surface area of bubble $S_{b}=S_{A} / \mathrm{V}$.

Geometric mean diameter (Sauter) $d_{b s}$ was adopted to characterize the mean diameter of such bubbles, as shown in the following formula:

$$
d_{b s}=\sum \frac{n_{i} d_{b i}{ }^{3}}{n_{i} d_{b i}{ }^{2}}
$$

$n_{i}-$ the number of bubbles with diameter.

\section{Results and Discussion}

\section{Analysis of Oxygen Mass Transfer}

\section{Influence of Atmospheric Reoxygenation}

The experimental device was a tank without cover, considering that the aeration oxygenation experiment was disturbed by external atmospheric reoxygenation, the influence of atmospheric reoxygenation on aeration was first explored through a pre-experiment before the formal experiment. Clean water was added to the water tank to a specified height, and nitrogen was filled to deoxidize the water body. After the DO was reduced to zero and stabilized, the portable oxygen dissolved meter was placed at the same position as the subsequent oxygen-mass-transfer experiment. The change trend of the DO over time was then measured, and results are shown in Fig. 4.

Fig. 4 shows that under the condition of atmospheric reoxygenation only, the concentration of DO showed a slow growth in the early stage (in the first 3 days, the concentration of DO increased from $0 \mathrm{mg} / \mathrm{L}$ to $0.5 \mathrm{mg} / \mathrm{L}$ ), and the growth rate in the later stage increased significantly. This trend was basically consistent with previous conclusions [37]. The difference was that the DO in the current work rose more slowly in the early stage, which was probably due to the relatively deeper DO probe in this experiment. Combined with 


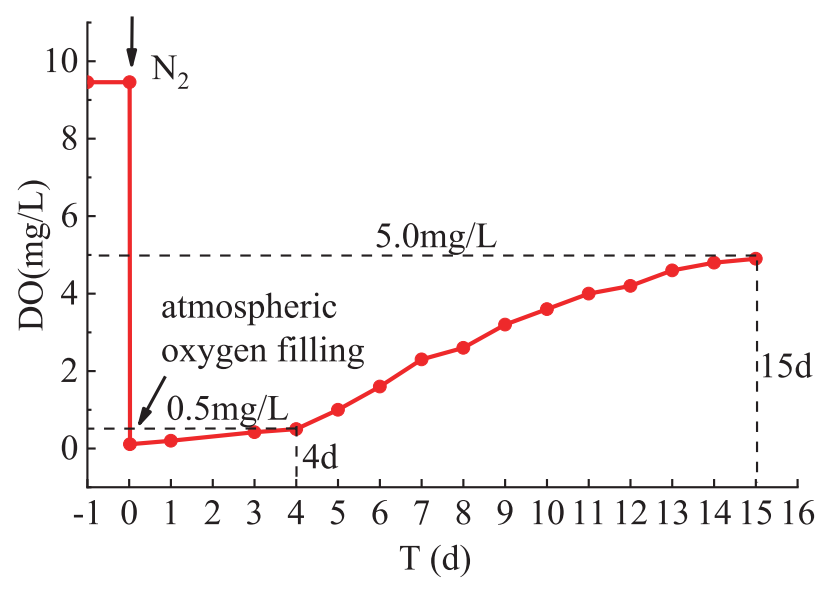

Fig. 4. Trend diagram of DO over time under atmospheric reoxygenation.

the aeration oxygen-mass-transfer experiment described later in this paper, DO can be known to reach saturation in a very short time (combined with Fig. 5, saturation can be known to be reached within 60-100 min). The influence of atmospheric reoxygenation on the
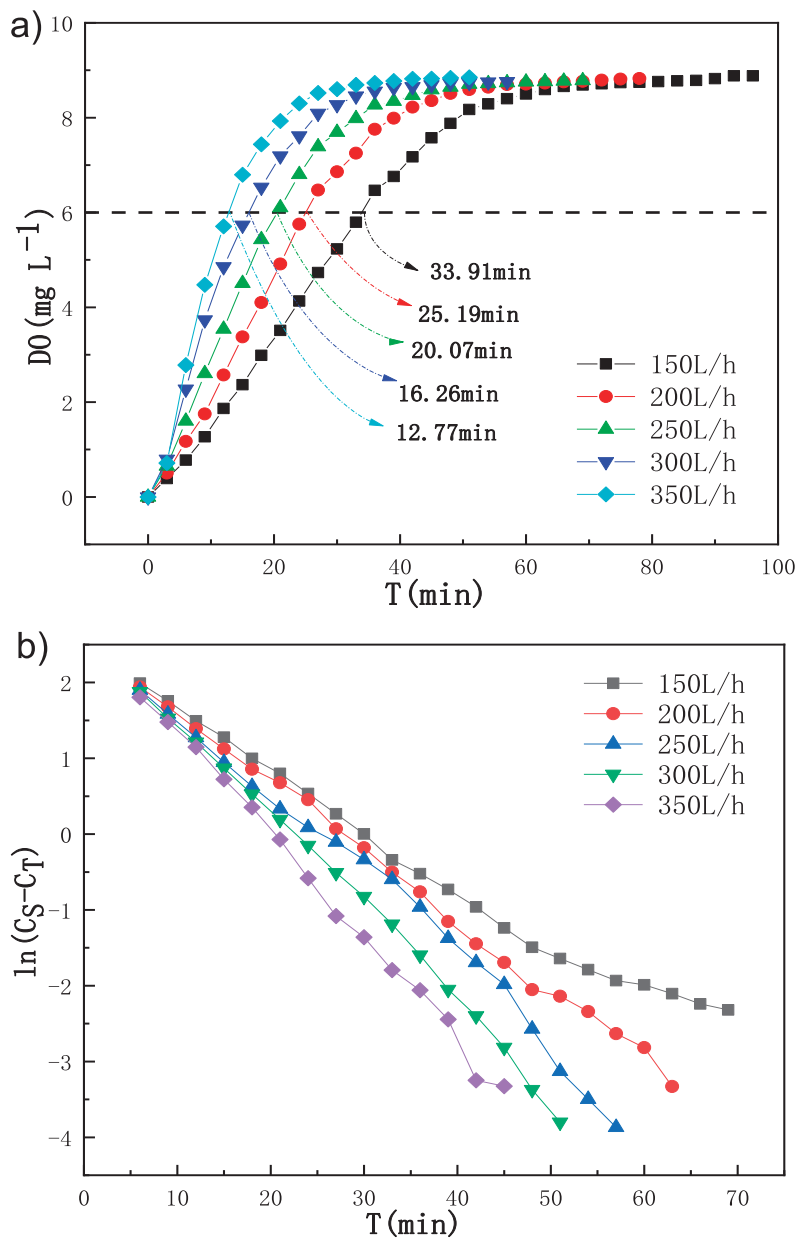

Fig. 5. Determined dissolved oxygen values over time plotted on a linear scale a) and decrease plotted on a log scale b) under different airflow rates. subsequent aeration oxygen-mass-transfer experiment can be ignored.

\section{Influence of Aeration on the Characteristics of Oxygen Mass Transfer}

Oxygen mass transfer was determined by experiments based on the measured DO values, which were used to calculate $K_{L} a$. Fig. 5a) shows that increased aeration rate accelerated the rate of rise of DO concentration. When DO concentration reached $6 \mathrm{mg} / \mathrm{L}$, the times required under different aeration rates (from $150 \mathrm{~L} / \mathrm{h}$ to $350 \mathrm{~L} / \mathrm{h}$ ) were $33.19,25.19,20.07$, 16.26 , and $12.77 \mathrm{~min}$, respectively.

By plotting these data on a log scale (Fig. 5b), $K_{L} a$ could be calculated for each airflow. To improve the accuracy of experimental data, the first two records and the second two records were omitted, and the relationship between $\ln \left(C_{s}-C_{t}\right)$ and time $\mathrm{T}$ is shown in Fig. $5 b$ ). The trend line equations of $150 \mathrm{~L} / \mathrm{h}$ to $350 \mathrm{~L} / \mathrm{h}$ are as follows: $\mathrm{y}=-3.7526 \mathrm{x}+2.9027, \mathrm{y}=-5.0862 \mathrm{x}$ $+2.9829, \mathrm{y}=-6.3918 \mathrm{x}+3.0624, \mathrm{y}=-7.6 \mathrm{x}+2.9449$, $\mathrm{y}=-8.1577 \mathrm{x}+2.7198$. The $K_{L} a$ varied from $3.75 \mathrm{~h}^{-1}$ (at $150 \mathrm{~L} / \mathrm{h}$ ) to $8.16 \mathrm{~h}^{-1}$ at $350 \mathrm{~L} / \mathrm{h}$ before correction of temperature, and the normalized $K_{L} a_{(20)}$ ranged from $3,70 \mathrm{~h}^{-1}$ to $7.99 \mathrm{~h}^{-1}$ (Table 1) after correction for the actual temperature $\left(K_{L} a_{(20)}\left(\mathrm{h}^{-1}\right)=K_{L} a_{(20)}\right.$ $\left(\mathrm{h}^{-1}\right) \times 1.024^{(20-\mathrm{T})}$. The oxygenation capacity $(O C)$ and oxygen-utilization rate $\left(E_{A}\right)$ can be obtained from the above formulas (4) and (5), respectively. This finding corresponded to an $O C$ in the range of $6.92 \mathrm{~g} \mathrm{O}^{2} \mathrm{~h}^{-1}$ to $14.94 \mathrm{~g} \mathrm{O}^{2} \mathrm{~h}^{-1}$. Meanwhile, with increased aeration, $\mathrm{E}_{\mathrm{A}}$ showed an initial increase (from $15.24 \%$ at $150 \mathrm{~L} / \mathrm{h}$ to $16.80 \%$ at $250 \mathrm{~L} / \mathrm{h}$ ), and then it decreased rapidly to $15.24 \%$ at $350 \mathrm{~L} / \mathrm{h}$ (Table 1 ). In summary, increasing the aeration amount can improve the oxygen mass-transfer efficiency and oxygen filling capacity in absolute value. It is the most efficient when the oxygen-utilization rate was the highest, i.e., $250 \mathrm{~L} / \mathrm{h}$, from the point of view of energy consumption.

Overall, aeration has positive and negative effects on gas-liquid-oxygen mass transfer. The positive effect can be explained as follows. First, the gas holdup increased with increased aeration amount [38], which increased the total gas-liquid contact area and induced $K_{L} a$ and $O C$ to increase. Second, when the aeration volume increased, the bubble movement enhanced the watermixing effect and intensified the turbulence degree, which improved the oxygen-mass-transfer coefficient in two aspects: 1) reduction in thickness of the liquid film and weakening of mass-transfer resistance; and 2) the water body around the bubble was updated quickly, which was conducive to maintaining a large oxygen deficit. The negative effects were usually reflected as the aeration volume increased in two aspects. On one hand, the bubble diameter increased, and the specific surface area decreased; on the other hand, the bubblemovement speed increased and the residence time shortened, which was not conducive to the oxygen mass 
Table 1. Determination results of oxygen mass transfer.

\begin{tabular}{|c|c|c|c|c|c|c|}
\hline$Q(\mathrm{~L} / \mathrm{h})$ & $\mathrm{T}\left({ }^{\circ} \mathrm{C}\right)$ & $C_{s}(\mathrm{mg} / \mathrm{L})$ & $K_{L} a\left(\mathrm{~h}^{-1}\right)$ & $K_{L} a_{(20)}\left(\mathrm{h}^{-1}\right)$ & $O C\left(\mathrm{~g} \mathrm{O}_{2} \mathrm{~h}^{-1}\right)$ & $E_{A}(\%)$ \\
\hline 150 & 20.47 & 8.88 & 3.75 & 3.71 & 6.94 & 16.53 \\
\hline 200 & 20.64 & 8.83 & 5.09 & 5.01 & 9.37 & 16.74 \\
\hline 250 & 20.71 & 8.78 & 6.39 & 6.28 & 11.76 & 16.80 \\
\hline 300 & 20.75 & 8.76 & 7.60 & 7.46 & 13.96 & 16.62 \\
\hline 350 & 20.90 & 8.85 & 8.16 & 7.99 & 14.94 & 15.24 \\
\hline
\end{tabular}

transfer $[39,40]$. On the whole, the positive effect of gas volume increase was dominant, which induced $K_{L} a$ and $O C$ to increase, and $K_{L} a$ and $O C$ were positively correlated with aeration (the correlation coefficient $\mathrm{R}^{2}$ were 0.98 and 0.98 , respectively) (Fig. 6(a,b)). Obviously, $K_{L} a$ and $O C$ were related to the difference in plume-motion parameters generated by aeration, so the bubble flow-field distribution characteristics require further study.

The influence of aeration amount on $E_{A}$ is primarily reflected by the gradual decrease in $E_{A}$ when aeration amount increases [41]. When the ventilation is small, the bubble diameter is small, the specific surface area of the bubble is relatively large, the bubble-movement speed is small, the retention time in the water is long, more oxygen is transferred to the water per unit air volume, and $E_{A}$ is high; the opposite trends are true when $E_{A}$ is low. In the present study, $E_{A}$ initially increased and then decreased with increased aeration because the aerator used in the experiment was an elastic rubber hose, and fine holes were evenly distributed on the hose wall, when the inlet pressure was greater than the requirements of opening pressure, microbubbles formed after the holes were opened; conversely, when the inlet pressure was lower than the opening pressure, the hole closed automatically. According to the change rule of $E_{A}$ (Fig. 6c), due to insufficient air pressure, the pores on the aeration hose were not fully opened, and many bubbles did not enter the water body. Moreover, no gasliquid mass transfer occurred when the aeration rate was $150 \mathrm{~L} / \mathrm{h}$ or $200 \mathrm{~L} / \mathrm{h}$. When the aeration amount was more than $250 \mathrm{~L} / \mathrm{h}$, the pores were completely open, so $E_{A}$ decreased with increased aeration amount. In practice, when this material was used for aeration, the aeration amount at the highest oxygen-utilization rate should be considered because the energy consumption rate was the lowest.

The above content qualitatively revealed the influence mechanism of gas holdup and bubble movement on the change trend of $K_{L} a, O C$, and $E_{A}$ with increased aeration amount. Nevertheless, few quantitative studies have focused on the change in aeration amount affects the characteristic parameters of bubble-movement flow-field. The succeeding parts of this paper focus on the change characteristics of the bubble-movement flow-field with increased aeration amount.
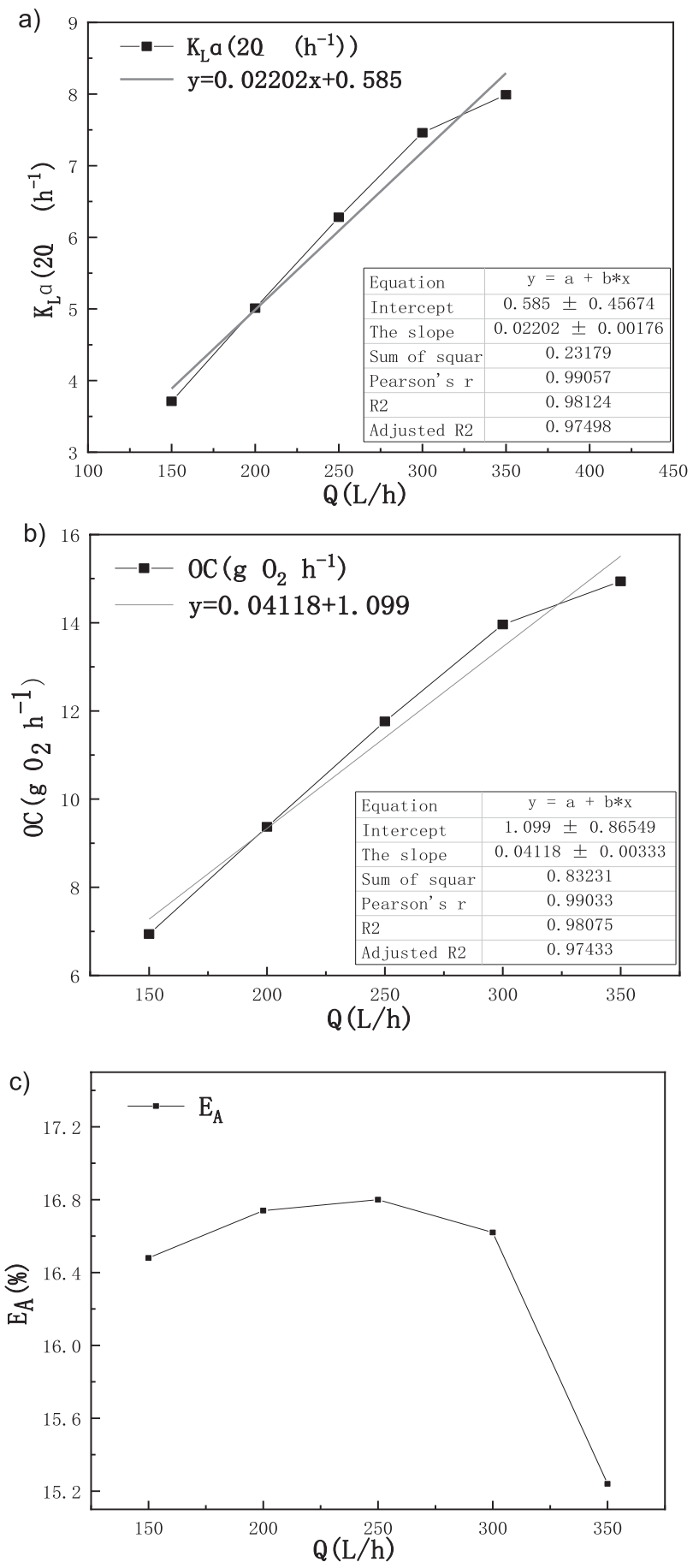

Fig. 6. Variation in characteristic parameters of oxygen mass transfer with time at different flow rates as represented by $K_{L} a$ a), $O C$ b), and $E_{A}$ c). 


\section{Influence of Aeration on the Gas Phase Vector Velocity Field}

\section{Influence of Aeration on the Gas Phase Velocity}

When the system had been stabilized, the shape of the bubble plume did not vary over time (data not shown). Fig. 7 shows the cloud map of average velocity of plume under different aeration rates. At an airflow of $150 \mathrm{~L} / \mathrm{h}$, the gas phase velocity was primarily located in the middle area of the aerator section and the velocity was generally low, with most of them concentrated in $0.2-0.25 \mathrm{~m} / \mathrm{s}$. With increased aeration volume to $250 \mathrm{~L} / \mathrm{h}$, the bubble plume range widened, showing the maximum velocity in the middle region, and a large number of bubbles had velocities between $0.35-0.4 \mathrm{~m} / \mathrm{s}$. When the aeration amount reached $350 \mathrm{~L} / \mathrm{h}$, the plume range continued to diffuse, the overall gas-phase velocity also increased accordingly, with a large number of bubbles reaching about $0.45 \mathrm{~m} / \mathrm{s}$. The figure above can be summarized as follows. 1) Under each aeration amount, the highbubble-velocity area was primarily concentrated in the middle area, and a larger aeration amount meant a higher proportion of the high-bubble-velocity area. 2) Bubble velocity decreased in gradient from the center to both sides, and the gradient difference increased from $0.2 \mathrm{~m} / \mathrm{s}$ to about $0.4 \mathrm{~m} / \mathrm{s}$ when $150 \mathrm{~L} / \mathrm{h}$ to $350 \mathrm{~L} / \mathrm{s}$ with increased aeration quantity. With increased air, the width of the bubble plume obviously increased, transverse impact amplitude rose from around $100 \mathrm{~mm}$ at $150 \mathrm{~L} / \mathrm{h}$ to about $300 \mathrm{~mm}$ at $350 \mathrm{~L} / \mathrm{h}$, and bubble turbulence degree increased. These phenomena benefited the gas and liquid two-phase mixture and improved the system's oxygen-filling capacity and oxygen-mass-transfer effect, further explaining the microscopic distribution of oxygen-mass-transfer characteristics.

\section{Influence of Aeration on the Gas phase Velocity Vector and Flow Pattern}

The vector heatmap in Fig. 7 shows the speed of bubbles in a given position, but their direction of movement is not shown. This direction can be visualized in the velocity-trajectory diagram of bubble movement (Fig. 8a). Fig. 8b) is the flow diagram of different aeration quantities extracted with TECPLOT software. As shown in Fig. 8a), when the aeration amount was 150 $\mathrm{L} / \mathrm{h}$, the main influence range of the bubble plume was $\mathrm{X}$ $=180-300 \mathrm{~mm}$. Bubble dispersion occurred when the $\mathrm{Y}$ direction was higher than $250 \mathrm{~mm}$, but the influence range remained limited. Meanwhile, Figs 8a) and 8b) show that the unaffected liquid phase on both sides of the bubble plume was at rest. When the aeration volume was $200 \mathrm{~L} / \mathrm{h}$, the influence range of bubble movement on the liquid phase increased, the left area showed a certain streamline trajectory, and the right part of the

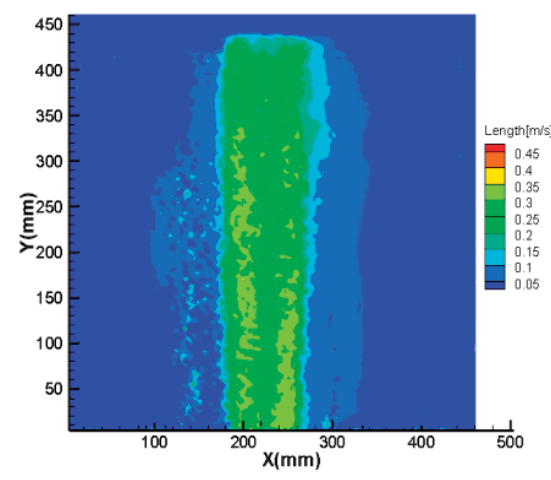

$150 \mathrm{~L} / \mathrm{h}$

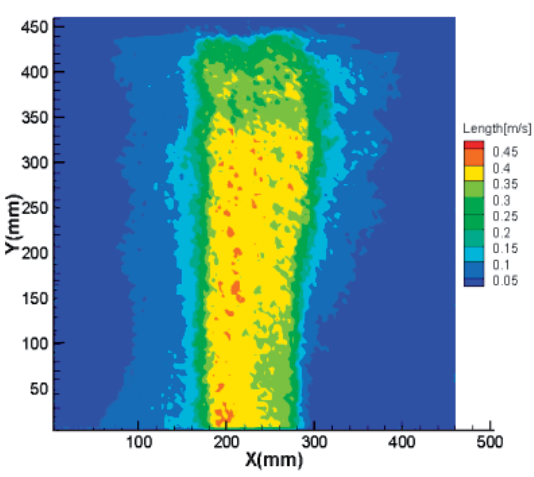

$200 \mathrm{~L} / \mathrm{h}$

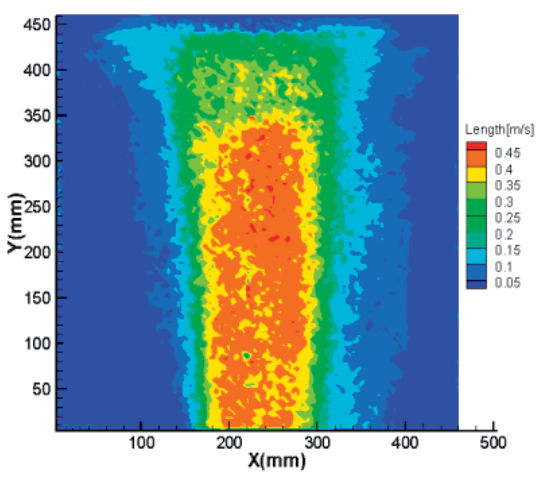

$250 \mathrm{~L} / \mathrm{h}$

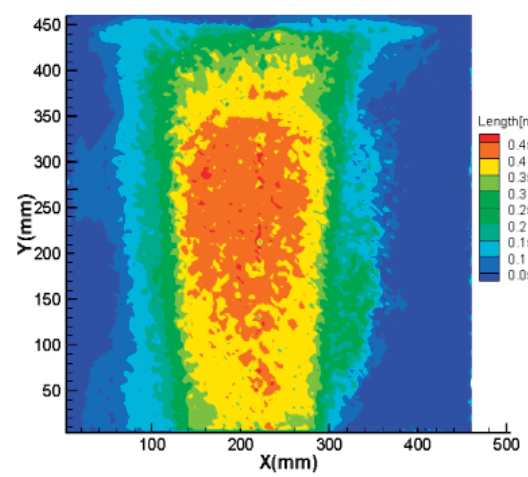

$300 \mathrm{~L} / \mathrm{h}$

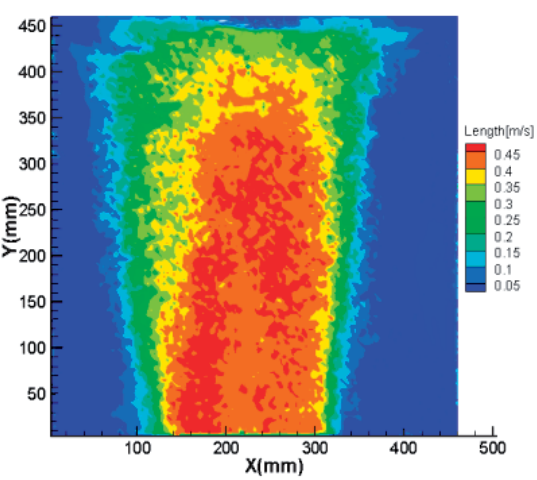

$350 \mathrm{~L} / \mathrm{h}$

Fig. 7. Corresponding velocity vector heatmaps of bubble plumes obtained with variable airflows, i.e., from $150 \mathrm{~L} / \mathrm{h}$ to $350 \mathrm{~L} / \mathrm{h}$, as indicated. For each airflow, an image obtained at around $t=6 \mathrm{~min}$ is shown. 
area still showed no plume. This finding can be seen in Fig. 8b) and Fig. 7 above. The movement track of bubble plume was primarily distributed in the region of $\mathrm{X}=150-350 \mathrm{~mm}$ at $250 \mathrm{~L} / \mathrm{h}$; at this time, the bubble plume began to form a hydraulic circulation in the left part. Fig. 8b) also indicate that the hydraulic circulation increased the degree of turbulence, promoting the gas-liquid two-phase exchange. When the aeration rate was $300 \mathrm{~L} / \mathrm{h}$, the movement track of bubble plume was primarily distributed in the region of $X=100-350 \mathrm{~mm}$, the water flow on both sides had been completely affected, and the hydraulic circulation gradually occurred on both sides, especially on the right side. The above phenomenon became more obvious

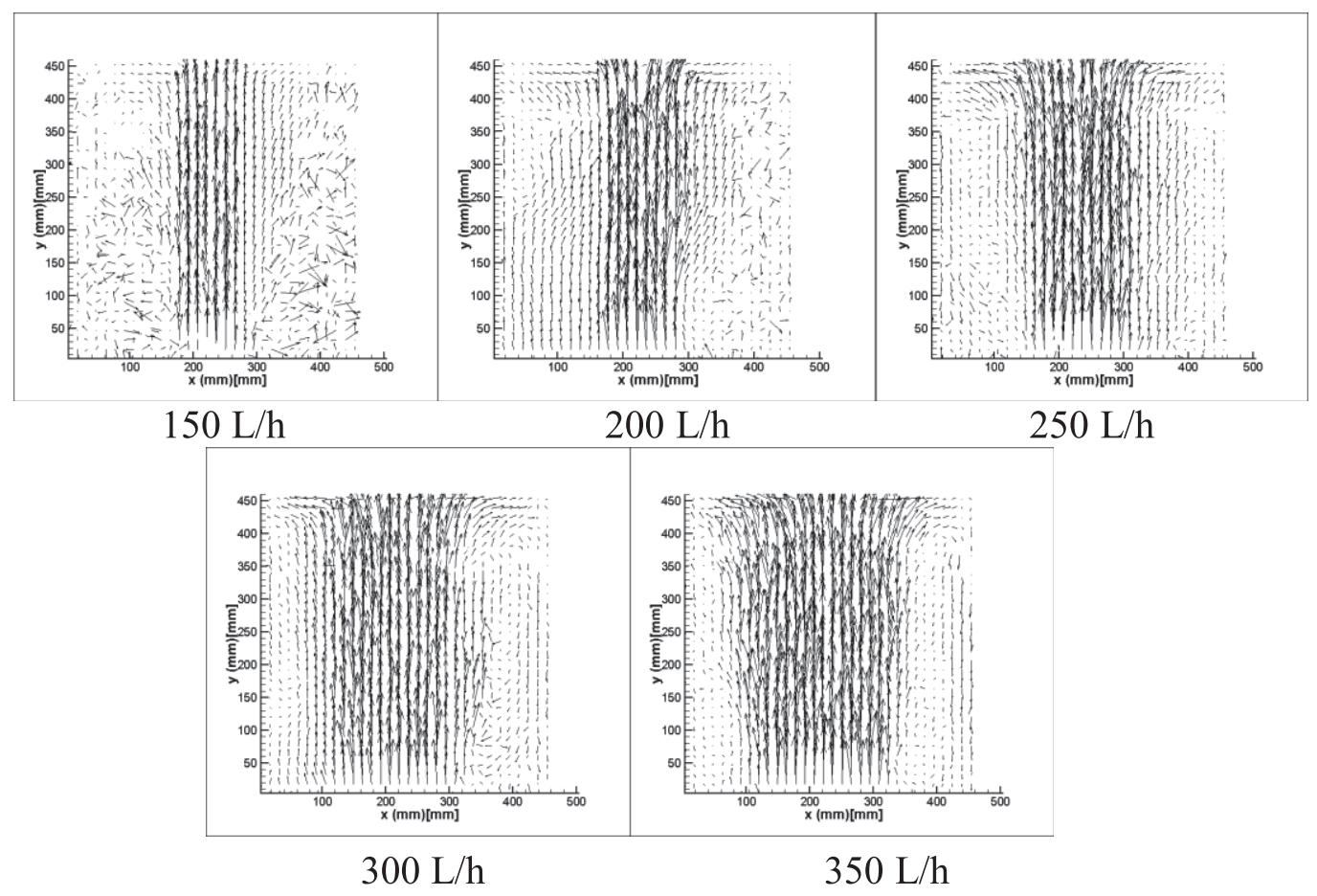

Fig. 8a) Corresponding direction of velocity vector heatmaps of bubble plumes obtained with variable airflows, from $150 \mathrm{~L} / \mathrm{h}$ to $350 \mathrm{~L} / \mathrm{h}$, as indicated. For each airflow, an image obtained at around $t=6 \mathrm{~min}$ is shown.
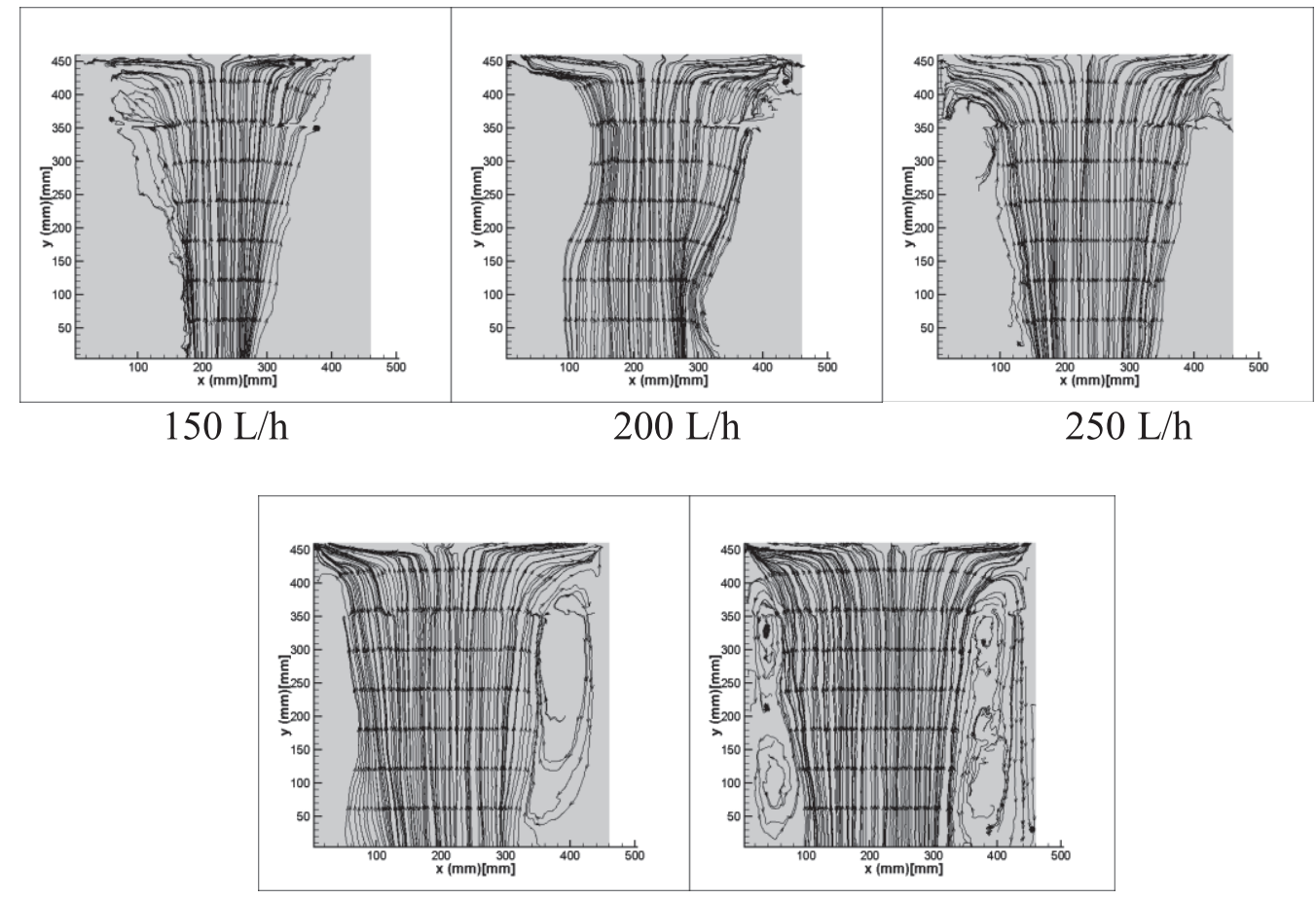

Fig. 8b) Bubble velocity-flow diagram under different airflows, from $150 \mathrm{~L} / \mathrm{h}$ to $350 \mathrm{~L} / \mathrm{h}$. 
and the movement track of bubble plume widened when the aeration amount reached $350 \mathrm{~L} / \mathrm{h}$, which fully affected the liquid on both sides and facilitated very obvious hydraulic circulation on both sides. These phenomena can also be clearly seen in Fig. 8b).

Combined with the cloud map of bubble-movement velocity, the increase in aeration volume led to the following. 1) The average bubble velocity gradually increased. Most bubbles were at $(0.2-0.25) \mathrm{m} / \mathrm{s}$ at $150 \mathrm{~L} / \mathrm{h}$ and increased to $250 \mathrm{~L} / \mathrm{h}$, but a large number of bubbles were at $0.35-0.4 \mathrm{~m} / \mathrm{s}$. Then, at $350 \mathrm{~L} / \mathrm{h}$, most bubbles were around $0.45 \mathrm{~m} / \mathrm{s}$. Combined with the analysis of the change rules of oxygen-mass-transfer experiment, it can be summarized as follows. On one hand, the increase in bubble-movement speed enhanced the degree of water turbulence, reduced the thickness of liquid film, accelerated the regeneration of water around bubbles, and induced bubble formation, rise, and breakage at a faster speed, thereby strengthening the oxygen mass transfer. On the other hand, the increase of bubble-movement speed can shorten retention time, which reduced the time of gas-liquid mass transfer and was not conducive to the oxygen mass transfer. Notably, the fact that bubble residence time influenced the oxygen mass transfer, which involved the time needed by the gas-liquid mass transfer, deserves further study. At present, in-depth research on this issue is lacking. 2) With increased aeration from $150 \mathrm{~L} / \mathrm{h}$ to $350 \mathrm{~L} / \mathrm{h}$, the bubble-velocity gradient (from the center to both sides of the edge) increased from $0.2 \mathrm{~m} / \mathrm{s}$ to about $0.4 \mathrm{~m} / \mathrm{s}$, which promoted the exchange between bubbles and water and increased the relative velocity between bubbles and water flow. The corresponding calculation formula of $K_{L} a$ was $K_{L} \mathrm{a}=2 \sqrt{\frac{D_{L} V_{r}}{\pi d_{b}} \frac{6 \mathrm{a}_{G}}{d_{b}}}$ [42], where $V_{r}$ is

the relative velocity between bubbles and water flow, as can be seen above, which increase improves $K_{L} a$. 3) With increased aeration, hydraulic circulation gradually occurred on both sides of bubble plume [43,44], which was very significant at $350 \mathrm{~L} / \mathrm{h}$. This phenomenon induced the bubble to produce strong wall-attachment effect, and the bubble aggregation collision intensified at the side wall of the aeration pool, which benefited the prolonging of bubble residence time and improvement in turbulent degree of the liquid phase. Ultimately, these phenomena aided gas-liquid two-phase mixing, improved the system's $O C$ and $K_{L} a$, and further explained the microscopic effect of oxygen-masstransfer distribution characteristics.

\section{Influence of Aeration on Characteristic Parameters of Bubble Plume}

Fig. 9 shows that the number of bubbles in the same field increased with increased aeration amount and was significantly positively correlated with the number of bubbles $(\mathrm{R}>0.98)$. The linear fitting equation was $\mathrm{N}=18.61 \mathrm{Q}-519.3$. With increased aeration amount from $150 \mathrm{~L} / \mathrm{h}$ to $350 \mathrm{~L} / \mathrm{h}$, the number of bubbles increased by $238.69 \%$, and the total surface area increased from $11004.84 \mathrm{~mm}^{2}$ to $37299.37 \mathrm{~mm}^{2}$ (Table 2). However, according to formulas (3) and (4), which improved $O C$ and $K_{L} a$, their variations were affected by many factors (e.g., bubble size, velocity, specific surface area, and other parameters), so further discussion is needed. Figs 9(b-d) show the variation in average Sauter diameter, specific surface area $\left(S_{b}\right)$, and proportion of bubble diameter under different aeration amounts $Q(L / h)$.

Fig. 9b) shows that with increased aeration amount from $150 \mathrm{~L} / \mathrm{h}$ to $350 \mathrm{~L} / \mathrm{h}$, the average bubble Sauter diameter increased from 1.48 to 1.77 (Table 2). A significant positive correlation existed between aeration and average Sauter diameter $(\mathrm{R}>0.97)$, and the linear fitting equation was dbs $=0.00154 \mathrm{Q}+1.225$. Due to the increase in aeration amount, a greater number of bubbles within the flow-field corresponded to a greater contact probability among bubbles, and larger bubbles were more likely to form with the collision and polymerization between them. Fig. 9c) shows the percentage of number of bubbles in each diameter range. Statistical analysis of the captured bubble diameter in the study area showed the following. 1) At each aeration rate, the diameter of bubbles greater than $80 \%$ was less than $2.0 \mathrm{~mm}$. 2) When bubble diameter ranged within $0-1.0 \mathrm{~mm}$, bubble proportion was the highest at $150 \mathrm{~L} / \mathrm{h}$, and the bubble proportion gradually decreased with increased aeration amount. 3) When the bubble diameter ranged within $1.0-2.0 \mathrm{~mm}$, bubble proportion was the lowest at $150 \mathrm{~L} / \mathrm{h}$, and bubble proportion gradually increased with increased aeration amount. In the subsequent $2.0-3.0 \mathrm{~mm}$, the change trend remained. 4) When the bubble diameter was greater than $3.0 \mathrm{~mm}$,

Table 2. Calculation table of bubble parameters under different aeration rates $(\mathrm{d}=200 \mu \mathrm{m})$.

\begin{tabular}{|c|c|c|c|c|c|}
\hline $\mathrm{Q}(\mathrm{L} / \mathrm{h})$ & $\begin{array}{c}\text { Number of bubbles } \\
\text { detected }\end{array}$ & $\begin{array}{c}\text { Sauter average } \\
\text { diameter }\left(d_{b s}\right)\end{array}$ & $\begin{array}{c}\text { Total surface area } \\
\left(\mathrm{mm}^{2}\right)\end{array}$ & $\begin{array}{c}\text { The total volume } \\
\left(\mathrm{mm}^{3}\right)\end{array}$ & $\begin{array}{c}\text { Specific surface } \\
\text { area }(\mathrm{S} / \mathrm{V})\left(\mathrm{mm}^{-1}\right)\end{array}$ \\
\hline 150 & 2557 & 1.48 & 11004.84 & 2824.66 & 3.90 \\
\hline 200 & 2935 & 1.49 & 13145.21 & 3433.88 & 3.83 \\
\hline 250 & 3923 & 1.63 & 18355.31 & 5179.06 & 3.54 \\
\hline 300 & 5148 & 1.68 & 28399.95 & 8242.05 & 3.45 \\
\hline 350 & 6103 & 1.77 & 37299.37 & 11495.21 & 3.24 \\
\hline
\end{tabular}


the bubble proportion decreased to a very low level without significant difference in each aeration volume, indicating that bubble diameter tended to increase with increased aeration amount, and the number of bubbles greater than $3.0 \mathrm{~mm}$ was very small. Fig. 9d) shows the change rule of specific surface area of bubbles under different aeration amounts, i.e., gas-liquid contact area per unit volume within the region. The figure shows that the specific surface area of the bubble decreased from 3.9 to 3.24 , with a decrease of $20.37 \%$ with increased aeration amount from $150 \mathrm{~L} / \mathrm{h}$ to $350 \mathrm{~L} / \mathrm{h}$ (Table 2). A significant negative correlation existed between aeration and specific surface area of bubbles $(\mathrm{R}<-0.98)$, and the linear fitting equation was $\mathrm{Sb}=-0.0034 \mathrm{Q}+4.442$, meaning that the gas-liquid contact area per unit volume decreased with increased aeration. This finding was not conducive to the process of oxygen mass transfer, and to a large extent revealed the reason why $\mathrm{E}_{\mathrm{A}}$ decreased with increased aeration.

Analysis of the variation law of oxygen mass transfer on the angle of flow-field characteristic parameters was conducted by Dong Liang [45]. They applied PIV technology to obtain a liquid velocity- vector diagram, flow diagram, and vorticity diagram and then analyzed flow-field motion to explain oxygen mass transfer. However, no combination of oxygenmass-transfer experiment and no quantitative analysis of bubble-movement characteristic parameters were used. Liu Xiao fang [46] measured parameters such as the diameter of microbubbles generated by the jet aerator by setting up a PIV test bench to explain oxygen mass transfer. However, they analyzed only the bubble size and did not combine it with oxygenmass-transfer experiments. In the present experiment, PIV technology was used to obtain the number of bubbles, average diameter of bubbles (Sauter), specific surface area of bubbles, and velocity field of bubbles. In quantitative terms, the results were as follows. 1) the bubble number $(\mathrm{R}>0.98)$ and the bubble-movement speed $((0.2-0.25) \mathrm{m} / \mathrm{s}$ at $150 \mathrm{~L} / \mathrm{h}$ to $0.45 \mathrm{~m} / \mathrm{s}$ at $350 \mathrm{~L} / \mathrm{h})$ were significantly positively correlated with increased aeration. Combined with the aforementioned, aeration flow was positively correlated with $K_{L} a\left(\mathrm{R}^{2}=0.98\right)$ and $O C\left(\mathrm{R}^{2}=0.98\right)$, showing that increased bubble number and bubble-movement velocity accelerated the oxygen mass transfer and improved the performance a)

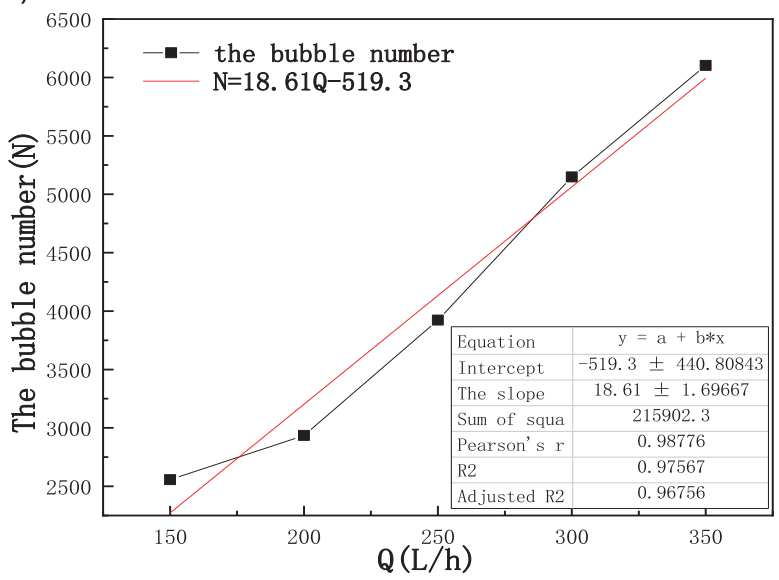

c)

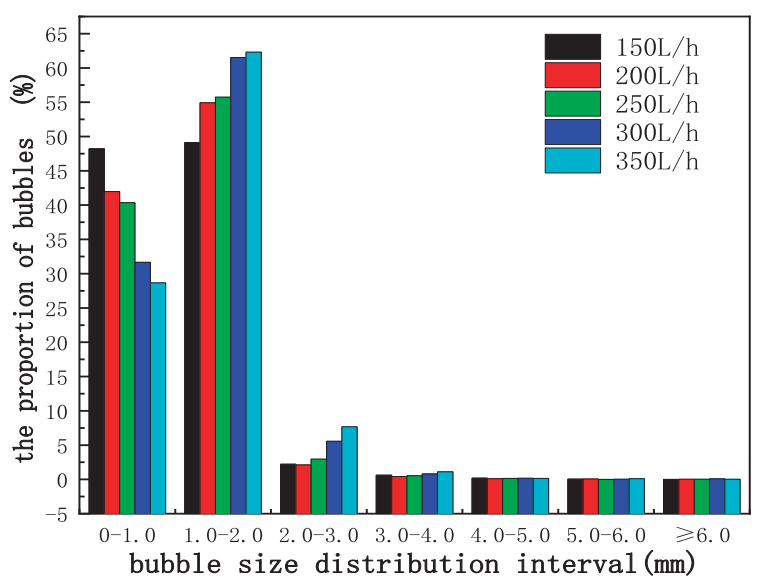

b)

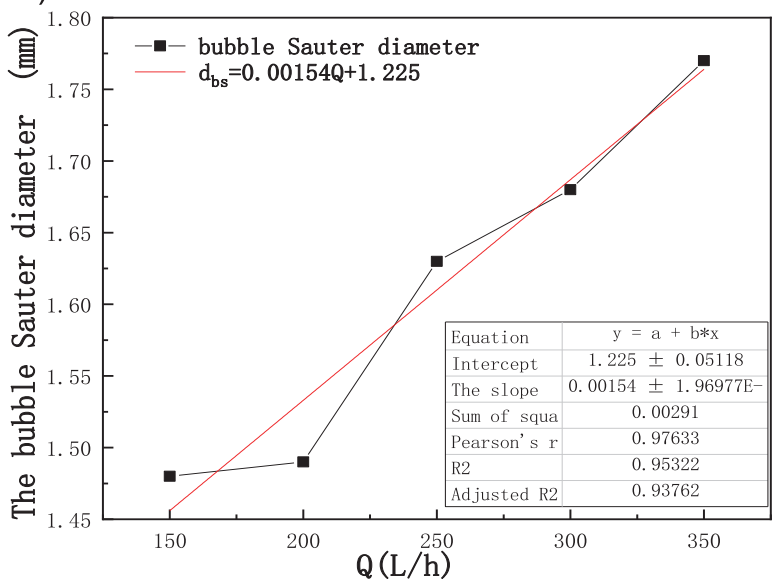

d)

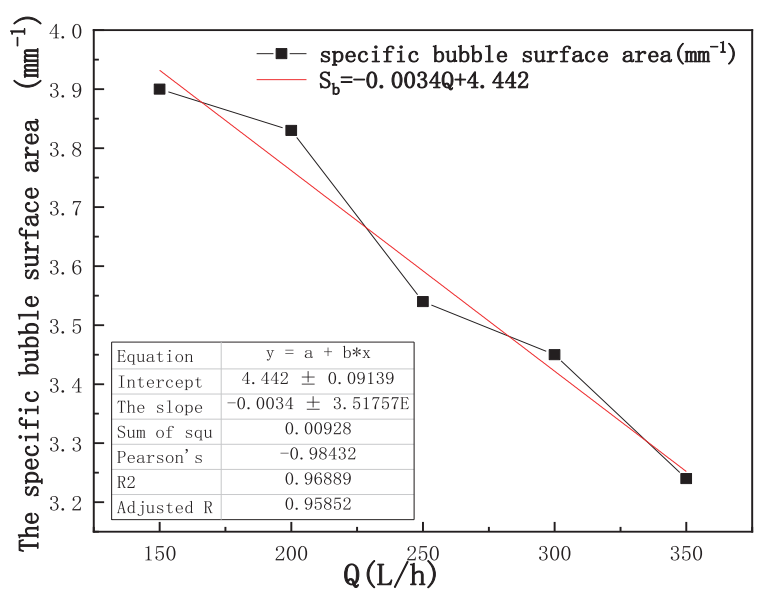

Fig. 9. Variation characteristics of bubble movement under different aeration flows: a) Variation characteristics of bubble number; b) Change rule of average Sauter diameter of bubbles; c) Characteristics of bubble size distribution; d) Characteristics of specific surface area of bubbles. 
of oxygen and $K_{L} a$. 2) A significant positive correlation existed between aeration and average Sauter diameter $(\mathrm{R}>0.97)$, and a significant negative correlation existed between aeration and specific bubble surface area $(\mathrm{R}<-0.98)$. The increase in aeration led to an increase in average bubble Sauter diameter, which reduced specific bubble surface area and $E_{A}$. 3) The increase of bubble diameter and bubble-movement velocity leads to the decrease of residence time in water, which may have lead to the decrease of oxygen mass transfer. The fact that the residence time of bubbles in the water affected the oxygen mass transfer may be related to the time needed for the oxygen mass transfer, which needs further research. In addition, some scholars have mentioned that the local dynamic characteristics of $K_{L} a$ [27] may be related to the characteristic parameters of bubble movement at each spatial position, and the functional relationship between $K_{L} a$ and each spatial position should be established. Thus, the author can see the deficiency of the research from this literature, that is, the research on oxygen-mass-transfer experiment and bubble-movement parameters should study the average value and the dynamics of $K_{L} a$. Nevertheless, in the present study, given the different aeration flows, the difference in the average value of characteristic parameters of bubble movement can still reflect the change mechanism of oxygen mass transfer to some extent.

\section{Conclusions}

The characteristic parameters of oxygen mass transfer and bubble-movement flow-field were investigated at different aeration rates to explain the characteristic parameters of oxygen mass transfer from the perspective of bubble-movement flow-field. The increase in bubble number (which can represent the gas holdup to some extent) and bubble velocity accelerated the oxygen mass transfer and improved the oxygenation performance and $K_{L} a$. The increase in the average diameter of bubble Sauter reduced the bubble specific surface area and $E_{A}$. Future work should focus on determining whether the change in bubble residence time in water affects oxygen mass transfer. $K_{L} a$ should also be combined with the specific location of bubblemovement parameters. The study explains the influence of bubble-movement characteristics on oxygen mass transfer and provides theoretical reference for research on improving oxygen mass-transfer efficiency through microporous aeration and enhanced water-restoration effect.

\section{Acknowledgements}

This research was financially supported by the National Natural Science Foundation of China (51809211).

\section{References}

1. ZHONG J.C., YOU B.S., FAN C.X., LI B., ZHANG L., DING S.M. Influence of Sediment Dredging on Chemical Forms and Release of Phosphorus. Pedosphere, 18 (1), 34, 2008.

2. MURPHY T.P., LAWSON A., KUMAGAI M., BABIN J. Review of emerging issues in sediment treatment. Aquatic Ecosystem Health \&amp; Management, 2 (4), 419, 1999.

3. BENTO F.M., CAMARGO F.A., OKEKE B.C., FRANKENBERGER W.T. Comparative bioremediation of soils contaminated with diesel oil by natural attenuation, biostimulation and bioaugmentation. Bioresource Technology, 96 (9), 1049, 2005.

4. AZCUE J.M., ZEMAN A.J., MUDROCH A., ROSA F., PATTERSON T. Assessment of sediment and porewater after one year of subaqueous capping of contaminated sediments in Hamilton Harbour, Canada. Water Science \&amp; Technology, 37 (6-7), 323, 1998.

5. ZOUMIS T., SCHMIDT A., GRIGOROVA L., CALMANO W. Contaminants in sediments: remobilisation and demobilization. Science of the Total Environment, 266 (1-3), 195, 2001.

6. LI Y., HUANG T.L., TAN X.L., ZHOU Z.Z., MA W.X. Destratification and oxygenation efficiency of a waterlifting aerator system in a deep reservoir: Implications for optimal operation. Journal of Environmental Sciences, $\mathbf{7 3}$ (11), 9, 2018.

7. TANG Q.L. Comparison of various aeration devices in the treatment of black and smelly water. China resources comprehensive utilization, 37 (07), 31, 2019.

8. HU P. Experimental Study on microporous aeration and Biofilm treatment of Rural Polluted Water Bodies. China Institute of Water Resources and Hydropower Research, 2015.

9. LU H., HU Z.B., JIANG Z., LIU K.H., YANG O.M., XIE X.Y. Effects of micro-nano aeration technology on urban landscape water restoration. Journal of environmental engineering, 10 (04), 1755, 2016.

10. QU J. Numerical Simulation and Experimental Study on Microporous aerated multiphase flow. Dalian University of Technology, 2017.

11. LI X.Y. Research on the reoxygenation technology of urban hard Navigable Water body. Zheng zhou University, 2015.

12. GAFSI M., KETTAB A., ABDELKADER D. Study of the oxygen transfer efficiencies in the Different Methods Used in the Technique of Hypolimnetic Aeration. Advance Materials Research, 1619, 1014, 2012.

13. MCGINNIS D.F., LORKE A., WÜEST A., STÖCKLI A., LITTLE J.C. Interaction between a bubble plume and the near field in a stratified lake. John Wiley \& Sons, Ltd. 40 (10), 11, 2004.

14. YIN X.F., QI L., ZHANG X.J., HE Z.J., ZHANG Y.K., WANG H.C. Research and numerical simulation of the influence of water depth on the oxygenation performance of microporous aeration. Water treatment technology, 41 (06), 75, 2015.

15. WANG H.X., JI Z.Y., LI X.G., QI Y.L. Study on mass transfer process of membrane oxygen supply. Chemical Engineering, 02, 33, 2008.

16. WU H.Z., WEI C., YU Z., WEI J.Y., WU C.F., WEI C.H. Theory and practice of oxygen mass transfer and enhancement in wastewater aerobic biological treatment process. Progress in Chemical Engineering, 37 (10), 4033, 2018. 
17. MARTÍN M., MONTES F.J., GALÁN M.A. Mass transfer rates from bubbles in stirred tanks operating with viscous fluids. Chemical Engineering Science, 65 (12), 3814, 2010.

18. HU P., LIU L.H., WU L.X., FANG Y.Y. Influence factors of microporous aeration aeration performance. Industrial water treatment, $35(08), 49, \mathbf{2 0 1 5}$.

19. LIU C., ZHANG L., YANG J.L., GUO J.B., LI Z.X. Research on oxygen mass transfer characteristics in micro-bubble aeration. Chinese Journal of Environmental Engineering, 4 (03), 585, 2010.

20. PANGARKAR V.G. Design of Multiphase Reactors. John Willey \& Sons Inc, New Jersey, Canada. 2015.

21. RAKOCZY R., LECHOWSKA J., KORDAS M., KONOPACKI M., FIJALKOWSKI K., DROZD R. Effects of a rotating magnetic field on gas-liquid mass transfer coefficient. Chemical Engineering Journal, 327, 608, 2017.

22. MCCLURE D.D., KAVANAGN J.M., FLETCHER D.F., BARTON G.W. Oxygen transfer in bubble columns at industrially relevant superficial velocities: experimental work and CFD modelling. Chemical Engineering Journal, 280, 138, 2015.

23. LI S.B., ZHU C.Y., FU T.T., MA Y.G. Study on the mass transfer of bubble swarms in three different rheological fluids. International Journal of Heat and Mass Transfer, $\mathbf{5 5}$ (21-22), 6010, 2012.

24. MUROYAMA K., IMAI K., OKA Y., HAYASHI J. Mass transfer properties in a bubble column associated with micro-bubble dispersions. Chemical Engineering Science, 100, 464, 2013.

25. TERASHIMA M., SO M., GOEL R., YASUI H. Determination of diffuser bubble size in computational fluid dynamics models to predict oxygen transfer in spiral roll aeration tanks. Journal of Water Process Engineering, 12, 120, 2016.

26. AZIZI S., YADAV A., LAU Y.M., HAMPEL U., ROY S., SCHUBERT M. On the experimental investigation of gas-liquid flow in bubble columns using ultrafast X-ray tomography and radioactive particle tracking. Chemical Engineering Science, 170, 320, 2017.

27. AMARAL A., BELLANDI G., REHMAN U., NEVES R., AMERLINCK Y., NOPENS I. Towards improved accuracy in modeling aeration efficiency through understanding bubble size distribution dynamics. Water Research, 131 (15), 346, 2018.

28. SIMIANO M., ZBORAY R., CACHARD F.D., LAKEHAL D., YADIGAROGLU G. Comprehensive experimental investigation of the hydrodynamics of largescale, 3D, oscillating bubble plumes. International Journal of Multiphase Flow, 32 (10), 1160, 2006.

29. RENSEN J., ROIG V. Experimental study of the unsteady structure of a confined bubble plume. International Journal of Multiphase Flow, 27 (8), 1431, 2001.

30. CHENG W., SONG C., ZHOU X.D. Numerical simulation and experimental study of gas-liquid two-phase flow in aeration tank. Chinese Journal of Water Resources, 12, 32, 2001.

31. WANG M. Experimental Research and Numerical Simulation of two-phase flow in gas-liquid reactor. Xi'an. Xi'an University of Technology, 2016.
32. XIAO B.Q., ZHANG F.X., LIU C.Y., LI R. Experimental study on wall enclosure effect of bubble plume in aeration tank. Journal of hydraulic power generation, 31 (04), 104$107+112,2012$

33. MOUTAFCHIEVA D., POPOVA D., DIMITROVA M., TCHAOUSHEV S. Experimental Determination of the volumetric mass transfer coefficient. Chem. Technol. Metall, 48 (4), 351, 2013.

34. YU M.S., NIU K.Y., KU K., HUANG W.X. Study on oxygen mass transfer characteristics in the aeration process of inner circulation biological fluidized bed. Shandong chemical industry, 43 (03), 10-12+15, 2014.

35. DENG X.W., LIU J.T., WANG Y.T., ZHANG C.X., XING B.L. Bubble size distribution in flotation column based on bottom swirl. Journal of china university of mining \& technology, 47 (05), 1092, 2018.

36. XIE Y.N. Aeration performance test and numerical simulation of microbubble diffusion aeration system. South China university of technology, 2018.

37. LI L.H., LUO W.S., HE T. Experimental Study on the theory of static Water and atmospheric reoxygenation. Journal of Wuhan University (Engineering Science edition), 05, 66, 2003.

38. WANG H.X., XIA W.C., YANG J.G., WANG H.W., ZHANG Z.L. Study on the influence of gas content and circulation on gas holdup of flotation column. Coal Engineering, 02, 85, 2011.

39. LI X.D., QI L., LIU G.H., ZHU F.F., ZHUANG J., LONG H.T., LUO T., WANG H.C. A pilot study on the influence of ventilation on the oxygenation performance of microporous aerator. China water and drainage, $\mathbf{3 0}(05)$, $81,2014$.

40. MCGINNIS D.F., LITTLE J.C. Predicting diffused- bubble oxygen transfer rate using the discrete-bubble model. Water Research, 36 (18), 4627, 2002.

41. HASEGAWA H., NAGASAKA Y., KATAOKA H. Electrical potential of microbubble generated by shear flow in pipe with slits. Fluid Dynamics Research, 40 (7-8), 554, 2008.

42. FAYOLLE Y., COCKX A., GILLOT S., ROUSTAN M., HÉDUIT A. Oxygen transfer prediction in aeration tanks using CFD. Chemical Engineering Science, 62 (24), 7163, 2007.

43. LI C.L., TIAN R., XING S.L., TAO Z.L., WEN J.L. Characteristics study of liquid flow field in membrane bioreactor based on PIV technology. China water supply and drainage. 29 (05), 85, 2013.

44. KARN A., SHAO S.Y., ARNDT R.E.A., HONG J.R., Bubble coalescence and breakup in turbulent bubbly wake of a ventilated hydrofoil. Experimental Thermal and Fluid Science. 70, 397, 2016.

45. DONG L., ZENG T., LIU S.B., WANG Y., ZHANG C.L., HE Y. Influence of inlet flow rate and aeration intensity on liquid phase flow and oxygen mass transfer characteristics of tubular aeration tank. Environmental pollution and prevention, 39 (11), 1246, 2017.

46. LIU X.F. PIV measurement of jet aeration fine bubbles. Journal of An hui university of technology (natural science edition), 29 (02), 167, 2012. 